\title{
Diketopyrrolopyrrole-based conjugated polymers with Perylene Bisimide side chains for single-component organic solar cells
}

Citation for published version (APA):

Lai, W., Li, C., Zhang, J., Yang, F., Colberts, F. J. M., Guo, B., Wang, Q., Li, M., Zhang, A., Janssen, R. A. J., Zhang, M., \& Li, W. (2017). Diketopyrrolopyrrole-based conjugated polymers with Perylene Bisimide side chains for single-component organic solar cells. Chemistry of Materials, 29(17), 7073-7077.

https://doi.org/10.1021/acs.chemmater.7b02534

DOI:

10.1021/acs.chemmater.7b02534

Document status and date:

Published: 12/09/2017

Document Version:

Accepted manuscript including changes made at the peer-review stage

Please check the document version of this publication:

- A submitted manuscript is the version of the article upon submission and before peer-review. There can be important differences between the submitted version and the official published version of record. People interested in the research are advised to contact the author for the final version of the publication, or visit the DOI to the publisher's website.

- The final author version and the galley proof are versions of the publication after peer review.

- The final published version features the final layout of the paper including the volume, issue and page numbers.

Link to publication

\footnotetext{
General rights

- You may freely distribute the URL identifying the publication in the public portal. follow below link for the End User Agreement:

www.tue.nl/taverne

\section{Take down policy}

If you believe that this document breaches copyright please contact us at:

openaccess@tue.nl

providing details and we will investigate your claim.
}

Copyright and moral rights for the publications made accessible in the public portal are retained by the authors and/or other copyright owners and it is a condition of accessing publications that users recognise and abide by the legal requirements associated with these rights.

- Users may download and print one copy of any publication from the public portal for the purpose of private study or research.

- You may not further distribute the material or use it for any profit-making activity or commercial gain

If the publication is distributed under the terms of Article $25 \mathrm{fa}$ of the Dutch Copyright Act, indicated by the "Taverne" license above, please 


\title{
Diketopyrrolopyrrole-based Conjugated Polymers with Perylene Bi- simide Side Chains for Single-Component Organic Solar Cells
}

\author{
Wenbin Lai, ${ }^{\dagger, \pm}$ Cheng Li,${ }^{\dagger}$ Jianqi Zhang, ${ }^{\dagger}$ Fan Yang,,${ }^{\dagger, \pm}$ Fallon J. M. Colberts, ${ }^{\S}$ Bing Guo, ${ }^{\perp}$ Qiang Mike \\ Wang, ${ }^{\S}$ Mengmeng Li, ${ }^{\S}$ Andong Zhang, ${ }^{\dagger, \pm}$ René A. J. Janssen, ${ }^{\S}$ Maojie Zhang ${ }^{\perp}$ and Weiwei Li ${ }^{*}{ }^{\dagger}$ \\ "Beijing National Laboratory for Molecular Sciences, Key Laboratory of Organic Solids, Institute of Chemistry, Chinese \\ Academy of Sciences, Beijing 100190, PR China. \\ ${ }^{*}$ National Center for Nanoscience and Technology, Beijing 100190, P. R. China. \\ ${ }^{\S}$ Molecular Materials and Nanosystems \& Institute for Complex Molecular Systems, Eindhoven University of Technology, \\ P.O. Box 513, 5600 MB Eindhoven (The Netherlands). \\ ${ }^{\perp}$ Laboratory of Advanced Optoelectronic Materials, College of Chemistry, Chemical Engineering and Materials Science, \\ Soochow University, Suzhou 215123, P. R. China. \\ ${ }^{ \pm}$University of Chinese Academy of Sciences, Beijing 100049, P. R. China.
}

\begin{abstract}
Three conjugated polymers based on diketopyrrolopyrrole (DPP) in the main chain and perylene bisimide (PBI) side chains were developed for application in singlecomponent organic solar cells. The crystallinity of the polymers was optimized using long dodecyl linkers between the DPP and PBI units and alkylthiothiophene groups on the benzodithiophene (BDT) units that alternate with DPP in the main chain. These side chains improve the nano-phase separation in the polymers, facilitating a high power conversion efficiency of $2.74 \%$ with broad photo-response between $300 \mathrm{~nm}$ and $900 \mathrm{~nm}$ in single-component solar cells.
\end{abstract}

The photoactive layers of organic solar cells have advanced from single conjugated materials to binary and multi-component blends. Presently a bulk-heterojunction (BHJ) consisting of an electron donor and electron acceptor represents the most successful approach with power conversion efficiencies (PCEs) over $13 \%$. Single-component organic solar cells (SCOSCs) have also received some attention, e.g. by developing conjugated block copolymers containing an electron donor and acceptor in one molecule to mimic the BHJ structure, but their performance is far from optimal..$^{2-7}$ This is mainly because it is difficult to realize the proper nano-phase separation between donor and acceptor in block copolymers, resulting in severe charge (hole and electron) recombination and low photocurrent in solar cells. ${ }^{8}$ In contrast, nano-phase separation in BHJ photoactive layers can be intentionally optimized, e.g. via tuning the crystalline properties of the conjugated materials or via the processing conditions. ${ }^{9}$ It seems to be a challenging task to realize nano-phase separation in singlecomponent conjugated materials in order to achieve high performance SCOSCs.

Herein we present the advantageous effects of increasing the length of the alkyl side chains and introducing heteroatoms through the synthesis of three single-component conjugated polymers in which the electron donor is located on the conjugated backbone and the electron acceptor in pendant side groups, also named as "double-cable" polymers. ${ }^{10-16}$ Conjugated block copol- ymers, including rod-coil ${ }^{17-18}$ and rod-rod ${ }^{19-21}$ structures, are the most studied single-component polymers for solar cells. However, due to the use of macro-monomers, most of block copolymers contain homopolymer impurities and defects, although they can be removed via some advanced methods such as quasi-living polymerization $^{16,22}$ and post-purification by preparative gel permeation chromatography (GPC). ${ }^{23}$ The "double-cable" conjugated polymers can effectively prevent these disadvantages, but their application in SCOSCs has been limited although they have been reported as early as $2001 .^{10-11}$ This is possible due to the difficulty to optimize the phase separation in these "double-cable" polymers, causing severely charge recombination in solar cells. Our design in this work is aiming to improve the nano-phase separation of these polymers so as to enhance their performance in SCOSCs.

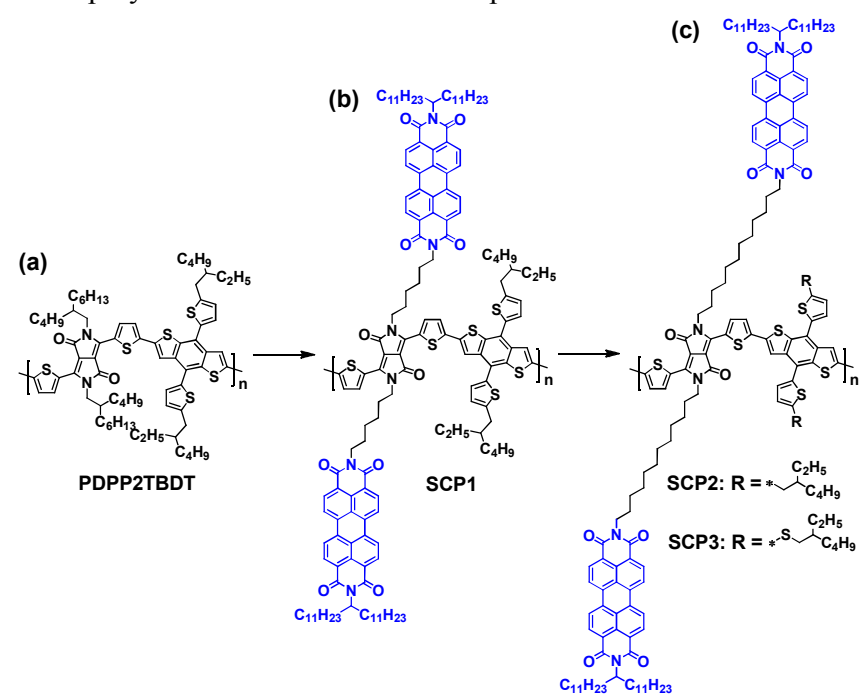

Scheme 1. Chemical structures of (a) DPP-polymer PDPP2TBDT. (b,c) Single-component polymers SCP1, SCP2 and SCP3 in this work.

The newly developed single-component conjugated polymers use diketopyrrolopyrrole (DPP)-based backbone and pendant perylene bisimide (PBI) as electron acceptor, connected with flex- 
ible alkyl side chains (Scheme 1). Semi-crystalline conjugated polymers based on DPP have been widely reported as electron donor and show high performance organic solar cells. ${ }^{24-27} \mathrm{PBI}$ derivatives with fused and twisted backbones have shown superior electron-transporting properties in non-fullerene solar cells. ${ }^{28-30}$ Therefore, it is interesting to incorporate the semi-crystalline DPP backbone and $\pi$-conjugated PBI units into one material. In this work, we select a near-infrared absorbing DPP-polymer PDPP2TBDT $^{31}$ (Scheme 1a) in which DPP is alternating with two-dimensional benzodithiophene (BDT) to construct the singlecomponent polymer SCP1, followed by tuning the distance between DPP and PBI to yield the polymer SCP2. Then SCP3 introduces alkylthiothiophene side chains on BDT. ${ }^{32}$ We demonstrate that the two structural modifications are able to improve the nanophase separation of the polymers and result in a PCE of $2.74 \%$ in SCP3-based SCOSCs compared to $0.51 \%$ based on SCP1 as photoactive layer.

The synthetic procedure for the monomers and polymers is shown in Scheme 2 and the detailed methods are presented in the Supporting Information (SI). Starting from the DPP compound M1, the key precursors M3 and M8 could be obtained via alkylation and bromination reactions, in which the four bromine atoms exhibit distinct reactivity. This enabled us to introduce PBI side chain into the DPP molecules by using mono-alkylated PBI compound M4, ${ }^{33}$ yielding the DPP-PBI monomers M5 and M9. The chemical structures of the precursors and monomers were confirmed by NMR and MALDI spectra, as shown in the Supporting Information. The polymers SCP1, SCP2 and SCP3 were prepared via Stille polymerization by using distannyl-BDT monomers M6 and M10 with alkylthiophene or alkylthio-thiophene side units. The polymers are readily soluble in $\mathrm{CHCl}_{3}$. The number-average molecular weight $\left(M_{\mathrm{n}}\right)$ determined by GPC measurement at $160{ }^{\circ} \mathrm{C}$ in 1,2,4-tricholorobenzene was $6.6,23.5$ and $20.7 \mathrm{~kg} \mathrm{~mol}^{-1}$ for the polymer SCP1, SCP2 and SCP3. All polymers show good thermal stability with $5 \%$ weight loss temperature above $340{ }^{\circ} \mathrm{C}$ (Figure S1).
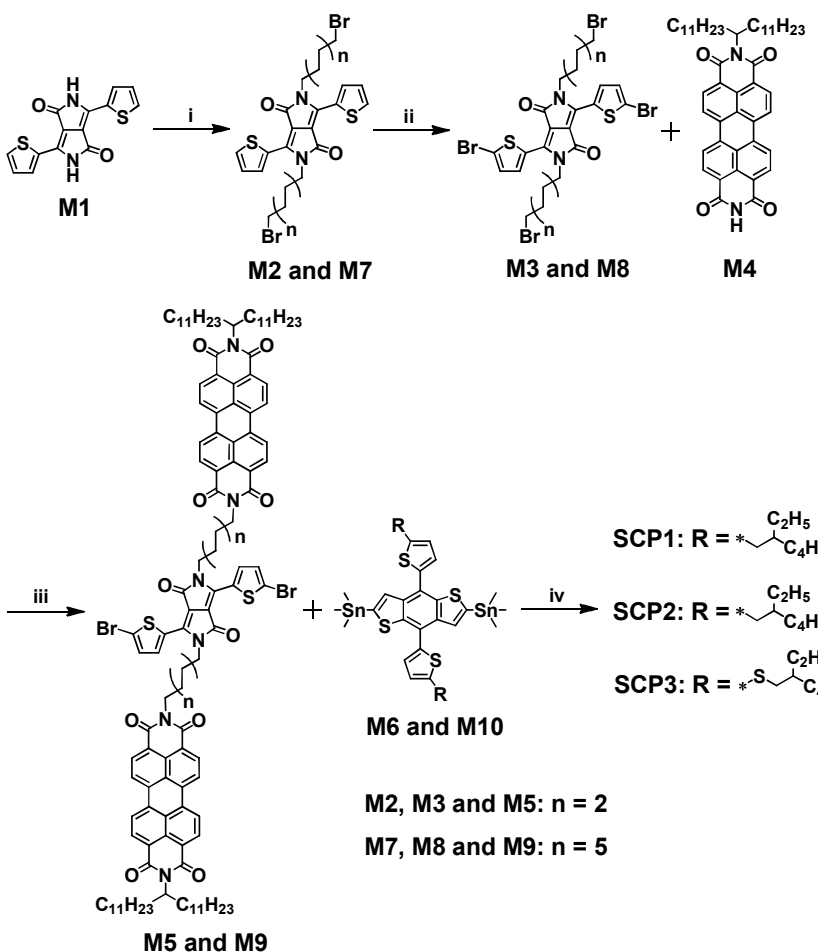

Scheme 2. Synthetic routes of the monomers and polymers. (i) $\mathrm{K}_{2} \mathrm{CO}_{3}$ in $\mathrm{DMF}$ at $120{ }^{\circ} \mathrm{C}, 18 \mathrm{~h}$; (ii) NBS in $\mathrm{CHCl}_{3}$; (iii) $\mathrm{K}_{2} \mathrm{CO}_{3}$ in DMF at $80{ }^{\circ} \mathrm{C}, 36 \mathrm{~h}$; (iv) Stille polymerization by using $\mathrm{Pd}\left(\mathrm{PPh}_{3}\right)_{4}$ in toluene/DMF $(10: 1, \mathrm{v} / \mathrm{v})$ at $115^{\circ} \mathrm{C}$.
The polymers SCP1 - 3 exhibit broad absorption spectra in the range of $300-900 \mathrm{~nm}$ with two distinct regions: region I located at $400-600 \mathrm{~nm}$ is attributed to the absorption of PBI units; region II at $600 \mathrm{~nm}-900 \mathrm{~nm}$ is from the absorption of DPP-polymer backbone and similar to that of PDPP2TBDT (Figure 1a, Figure $\mathrm{S} 2$ and Table $\mathrm{S} 1)$. SCP1 with a hexyl linker has a similar optical band gap $\left(E_{\mathrm{g}}=1.45 \mathrm{eV}\right)$ as PDPP2TBDT, but the absorption maximum in region II is significantly blue-shifted, indicating that the PBI units have significant impact on the $\pi-\pi$ stacking of conjugated backbone. When using long dodecyl linkers in SCP2 the absorption in region II and onset are red-shifted compared to PDPP2TBDT. This illustrates that longer alkyl linkage can effectively influence the impact of large PBI on the $\pi$ - $\pi$ stacking of polymer backbone. SCP3 with alkylthiothiophene units exhibits similar absorption spectra as SCP2. With respect to region I, it can be noted that the ratio of the intensity of the peaks of PBI at 530 and $492 \mathrm{~nm}$ decreases when going from SPC1 to SPC3. This peak ratio is sensitive to the $\pi-\pi$ stacking of $\mathrm{PBIs}^{34-35}$ and indicates that stacking of PBIs is more pronounced for SPC3 than for SPC1.
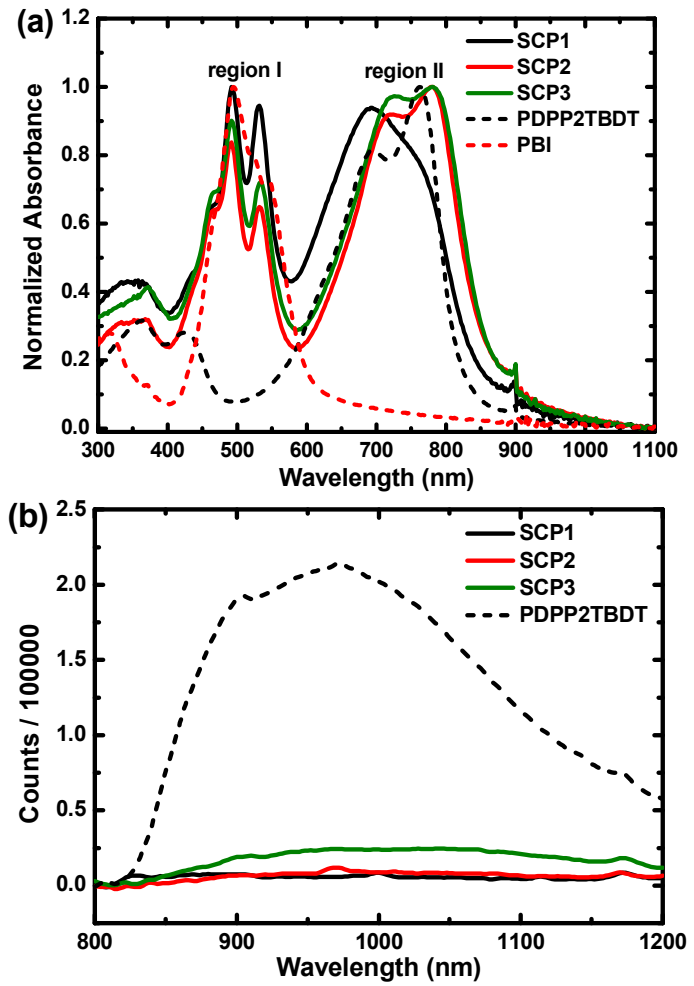

Figure 1. (a) Absorption spectra of the polymers and PBI in thin film. (b) Photoluminescence spectra of the polymers. The thin films were excited at $710 \mathrm{~nm}$. The quenching ratios at $972 \mathrm{~nm}$ are 37.0, 17.8 and 8.8 for SCP1, SCP2 and SCP3 compared to PDPP2TBDT.

The effects of the length of alkyl linker and alkylthiothiophene unit are also reflected in the steady-state photoluminescence (PL) spectra (Figure 1b). Compared to the emission of PDPP2TBDT, the PL of SCP1 - 3 was quenched, but the quenching ratio varied from 37.0 to 17.8 and 8.8. The lesser quenching in SCP2 and SCP3 is consistent with a more pronounced nano-phase separation in thin films. In BHJ systems with donor and acceptor, crystalline donor polymers can provide better nano-phase separation and the PL signals in blended thin films will be enhanced due to the presence of pure donor polymers domains. ${ }^{36}$ Therefore, we infer that in SCP1 thin films, the DPP-backbone and PBI are well-mixed, causing high PL quenching. When using the long alkyl linker or crystalline alkylthiothiophene units, the polymer backbone is able to self-aggregate, such that emission from the polymer backbone 
can be observed. The results are fully consistent with the optical absorption spectra for the three polymers.

The frontier orbital energy levels of the polymers determined by cyclic voltammetry measurement are shown in Figure S3 and Table S1. SCP1 and SCP2 possess similar energies of the highest occupied molecular orbital (HOMO) as PDPP2TBDT, while SCP3 has a slightly lower-lying HOMO level. This will enhance the open-circuit voltage $\left(V_{\mathrm{oc}}\right)$ in SCOSCs. The lowest unoccupied molecular orbital (LUMO) levels of the SCP1-3 located at lower position than that of PDPP2TBDT, which is due to the electrondeficient PBI units (Table S1).

The three polymers were then applied into SCOSCs with an inverted device configuration, using ITO/ZnO and $\mathrm{MoO}_{3} / \mathrm{Ag}$ electrodes. Optimization of the conditions for solution-processing of the photoactive layers is summarized in Tables S2 - S7. The performance of SCOSCs depends on thermal annealing temperature. The $J-V$ characteristics of the optimized cells are shown in Figure $2 \mathrm{a}$ and the parameters are summarized in Table 1 . BHJ solar cells based on PDPP2TBDT:PBI are included in SI for comparison.
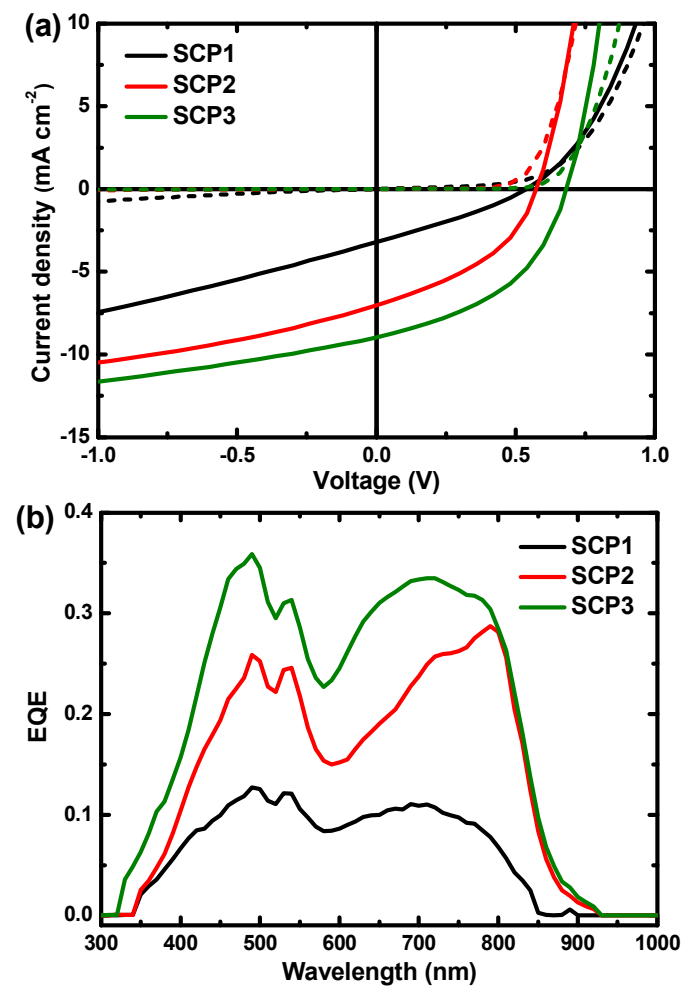

Figure 2. (a) $J-V$ characteristics in dark (dashed line) and under white light illumination (solid line). (b) EQE of the optimized SCOSCs.

Table 1. Characteristics of Optimized Solar Cells of the TPD Polymers with ITIC.

\begin{tabular}{lllll}
\hline Polymer & $\begin{array}{l}J_{\mathrm{sc}} \\
\left(\mathrm{mA} \mathrm{cm}{ }^{-2}\right)\end{array}$ & $\begin{array}{l}V_{\mathrm{oc}} \\
(\mathrm{V})\end{array}$ & $\mathrm{FF}$ & $\begin{array}{l}\mathrm{PCE}^{a} \\
(\%)\end{array}$ \\
$\mathrm{SCP}^{b}$ & $2.96 \pm 0.16$ & $0.54 \pm 0.005$ & $0.29 \pm 0.007$ & $0.47 \pm 0.03$ \\
& $(3.21)$ & $(0.54)$ & $(0.30)$ & $(0.51)$ \\
$\mathrm{SCP}^{\mathrm{c}}{ }^{\mathrm{c}}$ & $6.71 \pm 0.22$ & $0.57 \pm 0.007$ & $0.41 \pm 0.008$ & $1.58 \pm 0.06$ \\
& $(7.03)$ & $(0.57)$ & $(0.41)$ & $(1.64)$ \\
$\mathrm{SCP}^{d}$ & $8.28 \pm 0.36$ & $0.68 \pm 0.005$ & $0.46 \pm 0.014$ & $2.58 \pm 0.08$ \\
& $(8.96)$ & $(0.68)$ & $(0.45)$ & $(2.74)$ \\
\hline
\end{tabular}

${ }^{a}$ Statistics from 8 independent cells. The values in parentheses represent highest performance cells. ${ }^{\mathrm{b}}$ Fabricated from $\mathrm{CHCl}_{3} / o$ DCB $(10 \%)$ solution and thermally annealed at $200{ }^{\circ} \mathrm{C}$ for $10 \mathrm{~min}$. ${ }^{c}$ Fabricated from $\mathrm{CHCl}_{3} / o$-DCB (10\%) solution without thermal annealing. ${ }^{\mathrm{d}}$ Fabricated from $\mathrm{CHCl}_{3}$ and thermally annealed at $200{ }^{\circ} \mathrm{C}$ for $10 \mathrm{~min}$.

SCP1-based SCOSCs provided a low PCE of $0.51 \%$ with a short-circuit current density $\left(J_{\mathrm{sc}}\right)$ of $3.21 \mathrm{~mA} \mathrm{~cm}^{-2}$, a low $V_{\text {oc }}$ of $0.54 \mathrm{~V}$ and fill factor (FF) of 0.30 . The PCE was significantly enhanced to $1.64 \%$ in SCP2-based cells due to improved $J_{\text {sc }}$ of $7.03 \mathrm{~mA} \mathrm{~cm}{ }^{-2}$ and FF of 0.41 . SCP3-based SCOSCs showed the best PCE of $2.74 \%$ in these cells with a high $J_{\mathrm{sc}}$ of $8.96 \mathrm{~mA} \mathrm{~cm}{ }^{-2}$, $V_{\text {oc }}$ of $0.68 \mathrm{~V}$ and FF of 0.45 , which is doubled compared to PDPP2TBDT:PBI BHJ cells with a maximum PCE of $1.36 \%$ (Table S8). The enhanced $V_{\text {oc }}$ in SCP3-based cells is related to its deeper-lying HOMO level. The enhanced $J_{\mathrm{sc}}$ of these cells were reflected in their external quantum efficiencies (EQEs) (Figure 2b). All cells provide a broad photo-response from 300 to $900 \mathrm{~nm}$ with two distinct regions from PBI and DPP-polymer backbone, similar to their optical absorption spectra. SCP1-based cells showed EQEs below 0.1, while the EQE of SCP2-based cells was enhanced to above 0.2. The SCP3-based cells had the highest EQE with a maximum EQE of 0.35 . The calculated $J_{\text {sc }}$ from EQE spectrum were $2.77,6.37$ and $8.71 \mathrm{~mA} \mathrm{~cm}{ }^{-2}$, which is consistent with the $J-V$ measurements. Internal quantum efficiencies (IQEs) of the cells can also be calculated based on the refractive index and extinction coefficient of all layers in the device, in which SCP3-based cell showed IQE above 0.5, while IQE of SCP1 and SCP2 were below 0.5 and 0.3 . The average IQEs of SCP1 -3 based cells were $0.22,0.42$ and 0.57 that was consistent with their EQE spectra (Figure S5). Interestingly, the polymer SCP2 and SCP3 with dodecyl linkers also perform high absorption coefficiency compared to the polymer SCP1 with hexyl linkers (Figure S5b and c).

The enhanced $J_{\text {sc }}$ and FF in SCP2 and SCP3 based cells indicate better nano-phase separation between the polymer backbone and PBI units. Indeed, fiber-like structures can be observed in SCP2 thin films, as shown in atomic force microscopy (AFM) images (Figure S6). The morphology of these polymers was further studied by grazing-incidence wide-angle X-ray scattering (GIWAXS) and transmission electron microscopy (TEM), as shown in Figure 3 and Figure S7. From GIWAXS patterns, a clear enhanced crystallinity from SCP1 to SCP3 can be observed, as confirmed by the peaks located at in-plane (IP) (100) diffraction peaks and out-of-plane (010) diffraction peaks (Figure 3d-f). By using the full width at half maximum of the reflections, the crystal correlation length (CL) could be obtained, in which CL of (100) peaks was 2.0, 8.9 and $10.9 \mathrm{~nm}$ for SCP1 -3 (Table 2). CL of (010) peaks also showed the similar trends. The enhanced CL indicates that SCP2 and SCP3 are more crystalline in thin films reflected in the enhanced FF of the BHJ solar cells. This indicates that the charge transport efficiency is improved in the order of $\mathrm{SCP} 3>\mathrm{SCP} 2>\mathrm{SCP} 1$, as also observed in BHJ solar cells. ${ }^{37} \mathrm{TEM}$ confirms that crystalline domains are present in the active layer, although quite small $(<10 \mathrm{~nm})$. Due to the small length scale of interest and low contrast formation in these materials, no significant difference between the three samples could be observed.

Absorption, PL and GIWAXS results reveal that long alkyl linkages in SCP2 are able to improve the nano-phase separation between DPP and PBI, and alkylthiothiophene units strengthen the crystallinity of the polymer backbone. This will further provide better micro-phase separation in thin films, explaining the highest $J_{\mathrm{sc}}$ and FF in SCP3-based cells. It is also interesting to mention that, although the crystallinity in these single-component polymers is slightly reduced compared to PDPP2TBDT (Figure $\mathrm{S} 8)$, the $d$-spacings of $(010)$ peaks $(3.63 \AA)$ in these single- 
component polymers are significantly reduced compared to PDPP2TBDT (3.95 $\AA$ ) (Table 2 ). We infer that large $\pi$-conjugated PBI units with strong $\pi-\pi$ interaction are able to enhance the $\pi-\pi$ stacking of the conjugated backbone. This kind of condensed crystal packing would be helpful for charge transport in organic field-effect transistors.
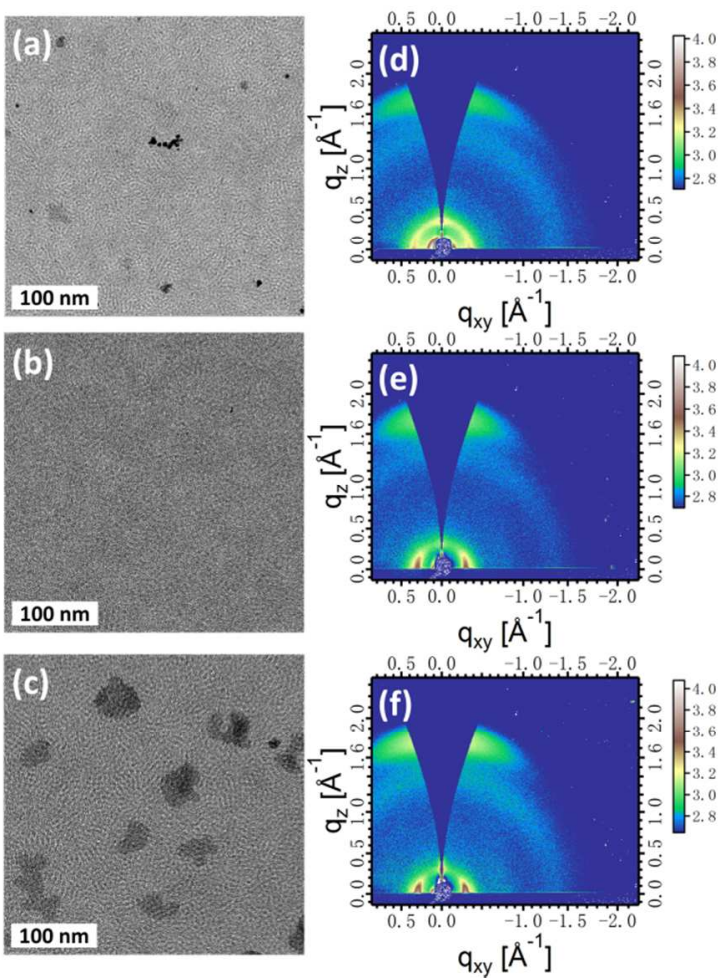

Figure 3. (a-c) Bright field TEM images and (d-f) GIWAXS images of the polymer thin films. (a,d) SCP1, (b,e) SCP2 and (c,f) SCP3.

Table 2. Crystallographic parameters of the pure polymer thin films.

\begin{tabular}{lllll}
\hline Polymer $^{a}$ & \multicolumn{3}{l}{ IP $(100)$} & OOP $(010)$ \\
\cline { 2 - 5 } & $d[\AA]$ & CL $[\mathrm{nm}]$ & $d[\AA]$ & CL $[\mathrm{nm}]$ \\
\hline SCP1 & 18.0 & 2.0 & 3.63 & 1.4 \\
SCP2 & 20.9 & 8.9 & 3.63 & 1.5 \\
SCP3 & 20.9 & 10.9 & 3.63 & 2.3 \\
PDPP2TBDT & 19.6 & 10.6 & 3.95 & 1.6 \\
\hline
\end{tabular}

${ }^{a}$ The solution-processed condition for the thin films is referred to Table $1 .{ }^{\mathrm{b}}$ Crystal correlation length $\mathrm{CL}=2 \pi / \mathrm{FWHM}$.

In conclusion, three new single-component conjugated polymers based on DPP-polymer backbone and PBI side chains were developed for SCOSCs. By introducing a long dodecyl linker between DPP and PBI units and alkylthiothiophene groups on BDT, the polymer SCP3 was found to show high crystallinity and better nano-phase separation compared to the polymer SCP1 with short hexyl linkers and alkylthiophene units. Consequently, a high PCE of $2.74 \%$ can be achieved in SCP3-based SCOSCs, while SCP1-based cells only provided a low PCE of $0.51 \%$. Our results clearly demonstrate that by finely tuning the chemical structures of single-component polymers, the nano-phase separation can be optimized to realize high performance SCOSCs.

\section{ASSOCIATED CONTENT}

\section{Supporting Information}

Materials and measurements, synthesis, TGA, absorption, CV, single-component and bulk-heterojunction solar cells, morphology and NMR spectra. This material is available free of charge via the Internet at http://pubs.acs.org.

\section{AUTHOR INFORMATION}

\section{Corresponding Author}

E-mail: liweiwei@iccas.ac.cn

\section{Author Contributions}

W. L and C. L. contributed equally.

\section{Notes}

The authors declare no competing financial interests.

\section{ACKNOWLEDGMENT}

We thank Prof. Jianhui Hou at Institute of Chemistry, Chinese Academy of Sciences for fruitful discussion and suggestion. This work was supported by the Recruitment Program of Global Youth Experts of China. The work was further supported by the National Natural Science Foundation of China (21574138, 51603209 and 91633301) and the Strategic Priority Research Program (XDB12030200) of the Chinese Academy of Sciences. The research also received funding from the European Research Council (339031) and from the Ministry of Education, Culture and Science (Gravity program 024.001.035).

\section{REFERENCES}

(1) Zhao, W.; Li, S.; Yao, H.; Zhang, S.; Zhang, Y.; Yang, B.; Hou, J., Molecular Optimization Enables over 13\% Efficiency in Organic Solar Cells. J. Am. Chem. Soc. 2017, 139, 7148-7151.

(2) Roncali, J., Single Material Solar Cells: the Next Frontier for Organic Photovoltaics? Adv. Energy Mater. 2011, 1, 147-160.

(3) Sommer, M.; Huettner, S.; Thelakkat, M., Donor-acceptor block copolymers for photovoltaic applications. J. Mater. Chem. 2010, 20, 10788-10797.

(4) Narayanaswamy, K.; Venkateswararao, A.; Nagarjuna, P.; Bishnoi, S.; Gupta, V.; Chand, S.; Singh, S. P., An Organic Dyad Composed of Diathiafulvalene-Functionalized Diketopyrrolopyrrole-Fullerene for Single-Component HighEfficiency Organic Solar Cells. Angew. Chem. Int. Ed. 2016, 55, 12334-12337. Bu, L. J.; Guo, X. Y.; Yu, B.; Qu, Y.; Xie, Z. Y.; Yan, D. H.; Geng, Y. H.; Wang, F. S., Monodisperse Co-oligomer Approach toward Nanostructured Films with Alternating Donor-Acceptor Lamellae. J. Am. Chem. Soc. 2009, 131, 13242-13243. Qu, J.; Gao, B.; Tian, H.; Zhang, X.; Wang, Y.; Xie, Z.; Wang, H.; Geng, Y.; Wang, F., Donor-spacer-acceptor 
monodisperse conjugated co-oligomers for efficient single-molecule photovoltaic cells based on non-fullerene acceptors. J. Mater. Chem. A 2014, 2, 3632-3640.

(7) Qu, J.; Liu, J.; Li, S.; Xie, Z.; Geng, Y., Donor-acceptor conjugated cooligomers for single molecule solar cells. Chin. J. Polym. Sci. 2013, 31, 815-822.

(8) Yamamoto, S.; Yasuda, H.; Ohkita, H.; Benten, H.; Ito, S.; Miyanishi, S.; Tajima, K.; Hashimoto, K., Charge Generation and Recombination in Fullerene-Attached Poly(3-hexylthiophene)Based Diblock Copolymer Films. J. Phys. Chem. C 2014, 118, 10584-10589.

(9) Huang, Y.; Kramer, E. J.; Heeger, A. J.; Bazan, G. C., Bulk Heterojunction Solar Cells: Morphology and Performance Relationships. Chem. Rev. 2014, 114, 7006-7043.

(10) Zhang, F.; Svensson, M.; Andersson, M. R.; Maggini, M.; Bucella, S.; Menna, E.; Inganäs, O., Soluble Polythiophenes with Pendant Fullerene Groups as Double Cable Materials for Photodiodes. Adv. Mater. 2001, 13, 1871-1874.

(11) Ramos, A. M.; Rispens, M. T.; van Duren, J. K. J.; Hummelen, J. C.; Janssen, R. A. J., Photoinduced Electron Transfer and Photovoltaic Devices of a Conjugated Polymer with Pendant Fullerenes. J. Am. Chem. Soc. 2001, 123, 6714-6715.

(12) Tan, Z.; Hou, J.; He, Y.; Zhou, E.; Yang, C.; Li, Y., Synthesis and Photovoltaic Properties of a Donor-Acceptor Double-Cable Polythiophene with High Content of C60 Pendant. Macromolecules 2007, 40, 1868-1873.

(13) Yuan, M.-C.; Su, M.-H.; Chiu, M.-Y.; Wei, K.-H., Synthesis and characterization of donor-bridge-acceptor alternating copolymers containing perylene diimide units and their application to photovoltaic cells. J. Polym. Sci., Part A: Polym. Chem. 2010, 48, 1298-1309.

(14) Gholamkhass, B.; Peckham, T. J.; Holdcroft, S., Poly(3hexylthiophene) bearing pendant fullerenes: aggregation vs. selforganization. Polym. Chem. 2010, 1, 708-719.

(15) Kohn, P.; Ghazaryan, L.; Gupta, G.; Sommer, M.; Wicklein, A.; Thelakkat, M.; Thurn-Albrecht, T., Thermotropic Behavior, Packing, and Thin Film Structure of an Electron
Accepting Side-Chain Polymer. Macromolecules 2012, 45, 56765683.

(16) Miyanishi, S.; Zhang, Y.; Hashimoto, K.; Tajima, K., Controlled Synthesis of Fullerene-Attached Poly(3-alkylthiophene)Based Copolymers for Rational Morphological Design in Polymer Photovoltaic Devices. Macromolecules 2012, 45, 6424-6437.

(17) Tao, Y.; McCulloch, B.; Kim, S.; Segalman, R. A., The relationship between morphology and performance of donoracceptor rod-coil block copolymer solar cells. Soft Matter 2009, 5, $4219-4230$

(18) Sommer, M.; Lang, A. S.; Thelakkat, M., CrystallineCrystalline Donor-Acceptor Block Copolymers. Angew. Chem. Int. Ed. 2008, 47, 7901-7904.

(19) Guo, C.; Lin, Y.-H.; Witman, M. D.; Smith, K. A.; Wang, C.; Hexemer, A.; Strzalka, J.; Gomez, E. D.; Verduzco, R., Conjugated Block Copolymer Photovoltaics with near 3\% Efficiency through Microphase Separation. Nano Lett. 2013, 13, 2957-2963.

(20) Lombeck, F.; Komber, H.; Sepe, A.; Friend, R. H.; Sommer, M., Enhancing Phase Separation and Photovoltaic Performance of All-Conjugated Donor-Acceptor Block Copolymers with Semifluorinated Alkyl Side Chains. Macromolecules 2015, 48, $7851-7860$

(21) Wang, J.; Higashihara, T., Synthesis of all-conjugated donor-acceptor block copolymers and their application in allpolymer solar cells. Polym. Chem. 2013, 4, 5518-5526.

(22) Chen, P.; Nakano, K.; Suzuki, K.; Hashimoto, K.; Kikitsu, T.; Hashizume, D.; Koganezawa, T.; Tajima, K., Organic Solar Cells with Controlled Nanostructures Based on Microphase Separation of Fullerene-Attached Thiophene-Selenophene Heteroblock Copolymers. ACS Appl. Mater. Interfaces 2017, 9, $4758-4768$

(23) Wang, S.; Yang, Q.; Tao, Y.; Guo, Y.; Yang, J.; Liu, Y.; Zhao, L.; Xie, Z.; Huang, W., Fully conjugated block copolymers for single-component solar cells: synthesis, purification, and characterization. New J. Chem. 2016, 40, 1825-1833.

(24) Li, W.; Hendriks, K. H.; Wienk, M. M.; Janssen, R. A. J., Diketopyrrolopyrrole Polymers for Organic Solar Cells. Acc. Chem. Res. 2016, 49, 78-85. 
(25)

Liu, Y.; Li, G.; Zhang, Z.; Wu, L.; Chen, J.; Xu, X.; Chen, X.; Ma, W.; Bo, Z., An effective way to reduce energy loss and enhance open-circuit voltage in polymer solar cells based on a diketopyrrolopyrrole polymer containing three regular alternating units. J. Mater. Chem. A 2016, 4, 13265-13270.

(26) Choi, H.; Ko, S.-J.; Kim, T.; Morin, P.-O.; Walker, B.; Lee, B. H.; Leclerc, M.; Kim, J. Y.; Heeger, A. J., Small-Bandgap Polymer Solar Cells with Unprecedented Short-Circuit Current Density and High Fill Factor. Adv. Mater. 2015, 27, 3318-3324.

Ashraf, R. S.; Meager, I.; Nikolka, M.; Kirkus, M.; Planells, M.; Schroeder, B. C.; Holliday, S.; Hurhangee, M.; Nielsen, C. B.; Sirringhaus, H.; McCulloch, I., Chalcogenophene Comonomer Comparison in Small Band Gap DiketopyrrolopyrroleBased Conjugated Polymers for High-Performing Field-Effect Transistors and Organic Solar Cells. J. Am. Chem. Soc. 2014, 137, 1314-1321.

(28) Liu, Z.; Wu, Y.; Zhang, Q.; Gao, X., Non-fullerene small molecule acceptors based on perylene diimides. J. Mater. Chem. A 2016, 4, 17604-17622.

(29) Sisto, T. J.; Zhong, Y.; Zhang, B.; Trinh, M. T.; Miyata, K.; Zhong, X.; Zhu, X. Y.; Steigerwald, M. L.; Ng, F.; Nuckolls, C., Long, Atomically Precise Donor-Acceptor Cove-Edge Nanoribbons as Electron Acceptors. J. Am. Chem. Soc. 2017, 139, 5648-5651.

(30) Yang, F.; Li, C.; Feng, G.; Jiang, X.; Zhang, A.; Li, W., Bisperylene bisimide based conjugated polymer as electron acceptor for polymer-polymer solar cells. Chin. J. Polym. Sci. 2017, $35,239-248$

(31) Dou, L. T.; You, J. B.; Yang, J.; Chen, C. C.; He, Y. J.; Murase, S.; Moriarty, T.; Emery, K.; Li, G.; Yang, Y., Tandem polymer solar cells featuring a spectrally matched low-bandgap polymer. Nat. Photonics 2012, 6, 180-185.

Cui, C.; He, Z.; Wu, Y.; Cheng, X.; Wu, H.; Li, Y.; Cao, Y.; Wong, W.-Y., High-performance polymer solar cells based on a 2D-conjugated polymer with an alkylthio side-chain. Energy Environ. Sci. 2016, 9, 885-891. Wicklein, A.; Lang, A.; Muth, M.; Thelakkat, M., Swallow-

Tail Substituted Liquid Crystalline Perylene Bisimides: Synthesis and Thermotropic Properties. J. Am. Chem. Soc. 2009, 131, 1444214453.

(34) Giaimo, J. M.; Lockard, J. V.; Sinks, L. E.; Scott, A. M.; Wilson, T. M.; Wasielewski, M. R., Excited Singlet States of Covalently Bound, Cofacial Dimers and Trimers of Perylene3,4:9,10-bis(dicarboximide)s. J. Phys. Chem. A 2008, 112, 2322 2330.

(35) Veldman, D.; Chopin, S. M. A.; Meskers, S. C. J.; Groeneveld, M. M.; Williams, R. M.; Janssen, R. A. J., Triplet Formation Involving a Polar Transition State in a Well-Defined Intramolecular Perylenediimide Dimeric Aggregate. J. Phys. Chem. A 2008, 112, 5846-5857.

(36) Li, W.; Zhou, Y.; Viktor Andersson, B.; Mattias Andersson, L.; Thomann, Y.; Veit, C.; Tvingstedt, K.; Qin, R.; Bo, Z.; Inganäs, O.; Würfel, U.; Zhang, F., The Effect of additive on performance and shelf-stability of HSX-1/PCBM photovoltaic devices. Org. Electron. 2011, 12, 1544-1551.

(37) Li, W.; Hendriks, K. H.; Furlan, A.; Roelofs, W. S. C.; Meskers, S. C. J.; Wienk, M. M.; Janssen, R. A. J., Effect of the Fibrillar Microstructure on the Efficiency of High Molecular Weight Diketopyrrolopyrrole-Based Polymer Solar Cells. Adv. Mater. 2014, $26,1565-1570$. 

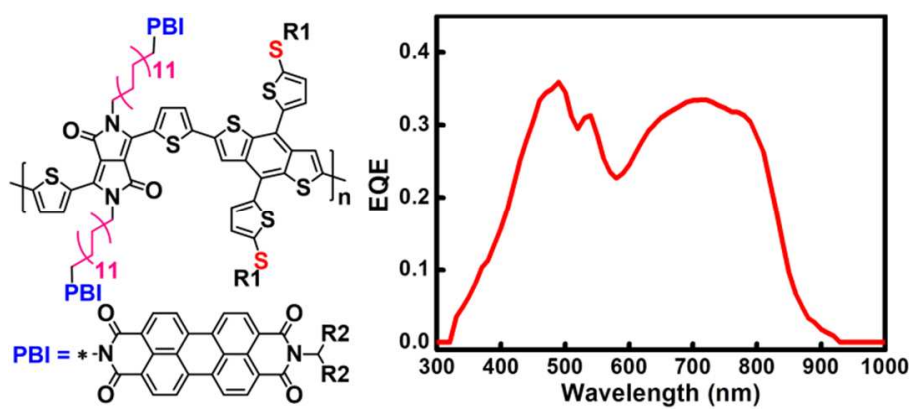